\title{
Further evidence for a viral etiology in plasmacytoid leukemia of chinook salmon Oncorhynchus tshawytscha
}

\author{
M. L. Kent, S. C. Dawe \\ Biological Sciences Branch, Department of Fisheries \& Oceans, Pacific Biological Station, Nanaimo, British Columbia, \\ Canada V9R 5K6
}

\begin{abstract}
Plasmacytoid leukemia (PL) is an important disease of seawater pen-reared chinook salmon Oncorhynchus tshawytscha in British Columbia, Canada. The disease is caused by an infectious agent, and the microsporidium Enterocytozoon salmonis, Renibacterium salmoninarum (the cause of bacterial kidney disease, BKD), and a retrovirus have been suggested as possible causes. Experimental transmission studies were conducted to elucidate the etiology of PL and they strongly indicate that a virus is the cause of the disease. The disease was transmitted using an inoculum prepared from affected kidney and spleen that had been passed through a $0.22 \mu \mathrm{m}$ filter. Oral treatment with Fumagillin DCH, an antiprotozoan compound used in other studies to treat $E$. salmonis infection, had no effect on the disease. Injection of $R$. saimoninarum that was isolated from a fish with PL caused BKD and no signs of PL.
\end{abstract}

\section{INTRODUCTION}

A plasmacytoid leukemia (PL) of chinook salmon Oncorhynchus tshawytscha, referred to as marine anemia by fish farmers, has caused mortality at many seawater netpen farms in British Columbia, Canada (Kent et al. 1990, Newbound \& Kent 1991a). Moribund fish with PL show reno-splenomegaly, serosanguinous ascites, and occasionally bilateral exophthalmus. Histological examination reveals massive proliferation of immature leucocytes, identified as plasmablasts, in the visceral organs and retrobulbar tissue (Kent et al. 1990). Although no etiologic agent for PL has been identified, the disease has been shown to be caused by an infectious agent. Plasmacytoid leukemia has been experimentally transmitted with tissue homogenates to chinook, sockeye O. nerka, and Atlantic salmon Salmo salar (Kent \& Dawe 1990, Newbound \& Kent 1991b).

Three agents have been suggested as possible causes of PL: the microsporidium Enterocytozoon salmonis, Renibacterium salmoninarum (the cause of bacterial kidney disease, BKD), and a retrovirus (Eaton \& Kent 1992). The microsporidium has been suggested to be the cause of similar proliferative diseases of salmonids in Washington (Morrison et al. 1990), California
(Hedrick et al. 1990), and Idaho, USA (MacConnell et al. 1991). Hedrick et al. (1991) reported that the antiprotozoan drug Fumagillin DCH could control the disease. Bacterial kidney disease, caused by $R$. salmoninarum, is a widespread disease in netpen-reared chinook, and is frequently observed in fish with PL. However, transmission studies indicated that the microsporidium and BKD are not the primary causes of PL because the disease could be transmitted in the absence of either (Kent \& Dawe 1990, Newbound \& Kent 1991b).

Essentially all infectious neoplasms are caused by oncogenic viruses, and Kent et al. (1990) suggested that an oncogenic virus (e.g. a retrovirus) might be the cause of PL. Evidence that support a retroviral etiology for PL includes reverse transcriptase activity in affected tissues at the appropriate density gradient for this family of viruses and visualization of retroviruslike particles by electron microscopy in both affected fish from the field and experimentally exposed fish (Eaton \& Kent 1992).

Three transmission studies were conducted to further elucidate the etiology of PL. The ability of an infectious agent to pass through a $0.22 \mu \mathrm{m}$ filter is used as strong evidence that the cause of a disease is a virus 
(Gross 1983). Therefore, we tested the ability of an inoculum containing the PL agent to remain infectious after passage through a $0.22 \mu \mathrm{m}$ filter. We also evaluated the efficacy of Fumagillin DCH to prevent PL because Hedrick et al. (1991) reported that it controlled a similar disease in California. In the third experiment, chinook were exposed to an isolate of Renibacterium salmoninarum obtained from a chinook with PL to determine if this bacterium (and specifically an isolate from a fish with PL) could cause PL.

\section{MATERIALS AND METHODS}

Three transmission studies were conducted in 7201 open-system tanks that received either fresh water (dechlorinated well water) or sand-filtered sea water. Recipient fish were from 2 strains of chinook maintained at the Pacific Biological Station: the Robertson Creek strain was used for the Renibacterium salmoninarum exposure study, and the Kitimat strain was used for the other experiments. Neither of these stocks had a history of PL.

Diagnosis. Confirmatory diagnosis of $\mathrm{PL}$ and BKD was based on histological examination. Tissues were fixed in Davidson's solution (Humason 1979), processed for histopathology using standard techniques, and sections were stained with either hematoxylin and eosin (H\&E) or periodic-acid Schiff's (PAS). Kidney imprints were stained with the Gram stain. Plasmacytoid leukemia was diagnosed by observing excessive numbers of blast cells, each with a large nucleus and a moderate amount of amphophilic cytoplasm, in the renal interstitium, spleen and at least one non-hematopoietic tissue (e.g. the lamina propria of the gut, liver. or the pancreas) (Kent et al. 1990). The histopathological changes associated with BKD have been previously described (Wood \& Yasutake 1956, Wolke 1975, Bruno 1986), and this disease was diagnosed by observation of multifocal, coalescing, granulomatous lesions in one or more of the following organs: kidney, liver, spleen, gut and/or mesenteries. The lesions were often necrotic and usually numerous, small, PAS-positive bacilli characteristic of Renibacterium salmoninarum were seen within phagocytes. The occurrence of large numbers of these Gram-positive bacilli in kidney imprints was also used to assist the diagnosis. The presence of Enterocytozoon salmonis was assessed by examining plasmablast nuclei in tissue sections stained with $\mathrm{H} \& \mathrm{E}$ at $\times 1000$

$0.22 \mu \mathrm{m}$ filtrate transmission. Ten chinook salmon (avg. wt $210 \mathrm{~g}$ ) were injected with $0.22 \mu \mathrm{m}$ filtrates of homogenized PL-affected tissue. Kidney and spleen tissue from 3 chinook with PL from another transmission experiment were pooled, and diluted $1: 4$ in
Minimum Essential Medium (MEM), and the preparation was thoroughly homogenized with a Polytron (Brinkman Instruments, Westburg, NY, USA). The homogenate was centrifuged at $1000 \times g$ for $10 \mathrm{~min}$, and the supernatant was prefiltered with a $1 \mu \mathrm{m}$ filter (Millipore Filter Corp., Bedford, MA, USA), and then filtered with $0.22 \mu \mathrm{m}$ tangential flow filters (Costar, Cambridge, MA). Each fish was injected intraperitoneally (IP) with $1 \mathrm{ml}$ of the $0.22 \mu \mathrm{m}$ filtrate. The fish were maintained in sea water at 10 to $12^{\circ} \mathrm{C}$.

To increase potential infection by a filterable agent, the fish were reinjected with another $0.22 \mu \mathrm{m}$ inoculum $60 \mathrm{~d}$ after first exposure (PI). The second inoculum was prepared as described above, but affected tissues were obtained from a pool of 3 fish with PL from a netpen site. Moribund and dead fish were collected and examined throughout the experiment, which was terminated at $100 \mathrm{~d}$ PI. Ten control fish, maintained in a separate aquarium, were examined at $101 \mathrm{~d}$ after the exposed fish were injected

Fumagillin efficacy. The efficacy of Fumagillin DCH for the control of PL was examined using experimentally infected chinook. Sixty chinook (avg. wt $60 \mathrm{~g}$ ) were exposed to PL by IP injection of affected spleen and kidney tissue. Tissues of 3 affected fish were pooled, and diluted 1:4 in Minimum Essential Medium (MEM), and the preparation was thoroughly homogenized with a Polytron (Brinkman Instruments, Westburg. NY). The recipient fish were each injected with $0.5 \mathrm{ml}$ inoculum. The fish were placed in 2 freshwater (ca $15^{\circ} \mathrm{C}$ ) tanks at 30 fish per tank.

One group was fed a commercial diet containing $0.1 \mathrm{~g}$ Fumagillin per $\mathrm{kg}$ feed, and the fish were fed at $1.5 \%$ of the body weight $\mathrm{d}^{-1}$. Thus, the treated fish received $1.5 \mathrm{mg}$ drug $\mathrm{kg} \mathrm{fish}^{-1} \mathrm{~d}^{-1}$. The drug contained $57 \%$ active ingredient and was incorporated into the diet as described by Hedrick et al. (1991). The treated fish were fed this diet throughout the experiment. The other group (controls) received the same diet that was untreated. Moribund and dead fish were examined throughout the study. In addition, random samples from each group were examined ( 6 fish per group at $26 \mathrm{~d}$ PI and 10 fish per group at $39 \mathrm{~d}$ PI). The study was terminated at $62 \mathrm{dPI}$, at which time the remaining 6 fish in the control group were examined.

Renibacterium salmoninarum exposure. Chinook salmon (avg. wt $36 \mathrm{~g}$ ) were exposed to 2 concentrations of a $R$. salmoninarum isolate obtained from a fish with PL to determine if the bacterium could induce PL. The bacterium was isolated on KDM-2 medium, incubated at $15^{\circ} \mathrm{C}$ for $3 \mathrm{wk}$, subcultured for $2 \mathrm{wk}$, and then suspended in sterile saline. Five fish were injected IP with ca $1 \times 10^{7}$ bacteria fish $^{-1}$ (high dose) and 5 fish were injected with ca $1 \times 10^{3}$ bacteria fish $^{-1}$ (low dose). Ten. control fish were injected IP with $0.1 \mathrm{ml}$ saline (a vol- 
ume equivalent to that used for the challenged fish). The fish were maintained in 2 separate tanks receiving sea water at ca $10^{\circ} \mathrm{C}$. Moribund fish were collected throughout the study, and examined by histology.

\section{RESULTS}

\section{$0.22 \mu \mathrm{m}$ filtrate transmission}

Most of the fish injected with the filtrate developed PL. The first fish in this group died at $45 \mathrm{~d}$ PI (in this case, PI indicates post-injection with the first inoculum), and 2 more fish died at 97 and $98 \mathrm{~d}$ PI. These fish exhibited reno-splenomegaly and ascites. The fish collected at 98 d PI had histological changes consistent with PL. All 3 fish had histological changes consistent $\mathrm{BKD}$ and imprints of their kidneys revealed numerous Renibacterium salmoninarum bacteria.

The experiment was terminated at $100 \mathrm{~d}$ PI and the remaining 7 fish were examined. The fish appeared clinically normal. Internally, all fish exhibited moderate to severe splenomegaly, and mild to moderate enlargement of the kidney, and one fish had a moderate amount serosanguinous ascites. Based on the pallor of the gills, the fish were moderately anemic. Histological examination revealed PL in all 7 fish. All of these fish exhibited extensive infiltration of plasmablasts in the spleen, kidney interstitium, lamina propria of the gut and liver (Fig. 1). One of the fish with PL also had BKD. Giemsa-stained blood smears demonstrated that the fish were leukemic, large numbers of plasmablasts being present (Fig. 2). Gram-positive bacilli were detected in a kidney imprint from the fish with BKD. Enterocytozoon salmonis was not detected in any fish.

Plasmacytoid leukemia was not observed in any of the control fish. One of the 10 control fish exhibited gross and histological changes consistent with BKD, and a few Renibacterium salmoninarum bacilli were observed in Gram-stained imprints of the kidney. The other 9 fish showed no gross or histological changes, and $R$. salmoninarum was not detected in kidney imprints in any of these fish. Thirty fish from the stock population that served as the source for the experiment were also examined because BKD was observed in the experimental fish. This sample was collected $46 \mathrm{~d}$ after experimental fish were injected with the $0.22 \mu \mathrm{m}$ filtrate. One fish showed gross and histological changes

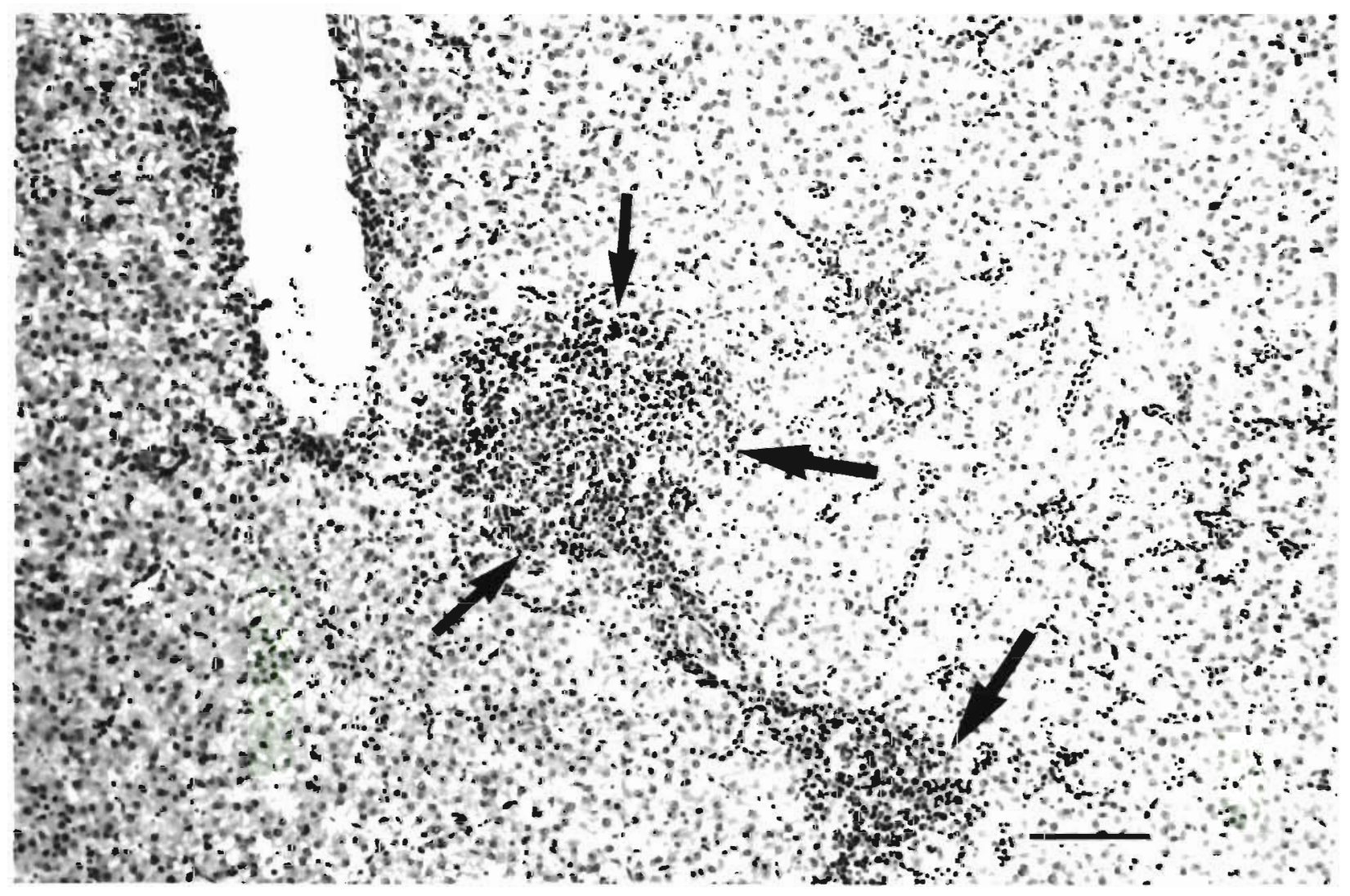

Fig. 1. Oncorhynchus tshawytscha. Proliferation of plasmablasts (arrow) in liver of a chinook with PL that was exposed by injection with $0.22 \mu \mathrm{m}$ filtrate. $\mathrm{H} \& \mathrm{E}$. Scale bar $=100 \mu \mathrm{m}$ 
consistent with BKD. The remaining fish appeared grossly normal, and histologic examination of 9 of them revealed no signs of PL or BKD. Gram-stained imprints of the kidney of the fish with clinical BKD revealed numerous $R$. salmoninarum bacilli, and the organism was detected in low numbers in kidney imprints of 3 of the remaining 29 fish.

\section{Fumagillin efficacy}

Oral treatment with Fumagillin DCH did not prevent or reduce PL. All of the treated and control fish developed PL, and most showed severe lesions. The first treated fish died with PL at $18 \mathrm{~d}$ post-injection (PI). Aside trom the 16 fish in the random sampies, all the fish in this group had died with PL by $40 \mathrm{~d}$ PI. The first control fish died with PL at $19 \mathrm{~d}$ PI, the last moribund fish from this group was collected at $44 \mathrm{~d}$ PI. The 6 remaining fish were collected at $62 \mathrm{~d}$ PI.

All fish in both groups showed massive proliferation of plasmablasts in the kidney and visceral organs (Fig. 3). Six fish in the treated group and 7 fish in the control group also exhibited BKD by histology. Enterocytozoon salmonis was not detected in any of the treated or control fish.

\section{Renibacterium salmoninarum exposure}

Fish injected with either level of Renibacterium salmoninarum eventually died or were collected when moribund and near death. All of these fish showed granulomatous lesions in the viscera typical of BKD, and none of the fish exhibited histological changes consistent with PL. The first fish from the high dose challenge group died at $18 \mathrm{dPI}$ and the last fish in the group died at $41 \mathrm{~d}$ PI. The first fish (which was moribund) in the low dose challenge group was examined at $46 \mathrm{~d}$ PI and the last surviving fish in this group was examined at $60 \mathrm{~d}$ Pl. The control fish were examined at $60 \mathrm{~d}$ PI and showed no signs of BKD.

\section{DISCUSSION}

These transmission experiments indicate that a filterable agent smaller than $0.22 \mu \mathrm{m}$ (i.e. a virus) is the cause of PL. The ability of an infectious agent to pass through a $0.22 \mu \mathrm{m}$ filter and cause a disease is generally considered as strong evidence that this agent is a virus or other extremely small microorganisms (e.g. a mycoplasma). Our experiments also indicate that Renibacterium salmoninarum and Enterocytozoon salmonis are not the cause of the disease. This concurs

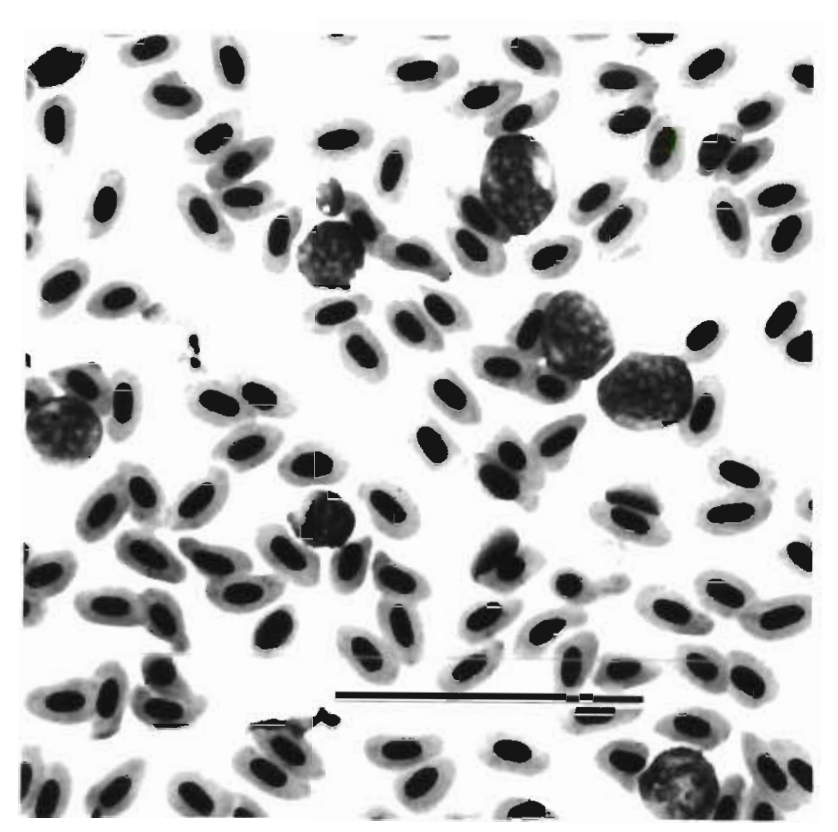

Fig. 2. Oncorhynchus tshawytscha. Plasmablasts in peripheral blood of chinook with PL that was exposed by injection with $0.22 \mu \mathrm{m}$ filtrate. Giemsa. Scale bar $=50 \mu \mathrm{m}$

with previous observations, in which many chinook with PL in netpens (Kent et al. 1989, 1990) and in experimental transmission studies (Newbound \& Kent 1991b) did not show E. salmonis infections or BKD.

In the present study, all fish injected with an isolate of Renibacterium salmoninarum obtained from a fish with PL exhibited BKD and no pathological changes consistent with PL. In the filtrate experiment, some control and challenged fish exhibited BKD, but only the latter developed PL. Therefore, although R. salmoninarum was present in both groups, only fish that received an infectious agent capable of passing through a $0.22 \mu \mathrm{m}$ filter, presumably a virus, developed PL. Most of the fish exposed to the filtrate were collected before they were allowed to become moribund. However, all of these fish exhibited histological changes typical of PL (Kent et al. 1990) and, therefore, unequivocally had the disease.

Based on these results and previous studies with PL (Eaton \& Kent 1992), this filterable agent is probably a retrovirus. Other infectious neoplasms of fish that can be transmitted by injection of a filterable agent (presumably oncogenic viruses) from affected tissues include lymphosarcoma of pike Esox lucius (Mulcahy \& O'Leary 1970), a plasma cell leukemia of brown bullhead Amerius (= Ictalurus) nebulosus (Sonstegard 1979, Gross 1983), dermal sarcoma of walleye Stizostedion vitreum (Martineau et al. 1990), and neurofibromatosis of damsel fish Pomacentrus partitus 


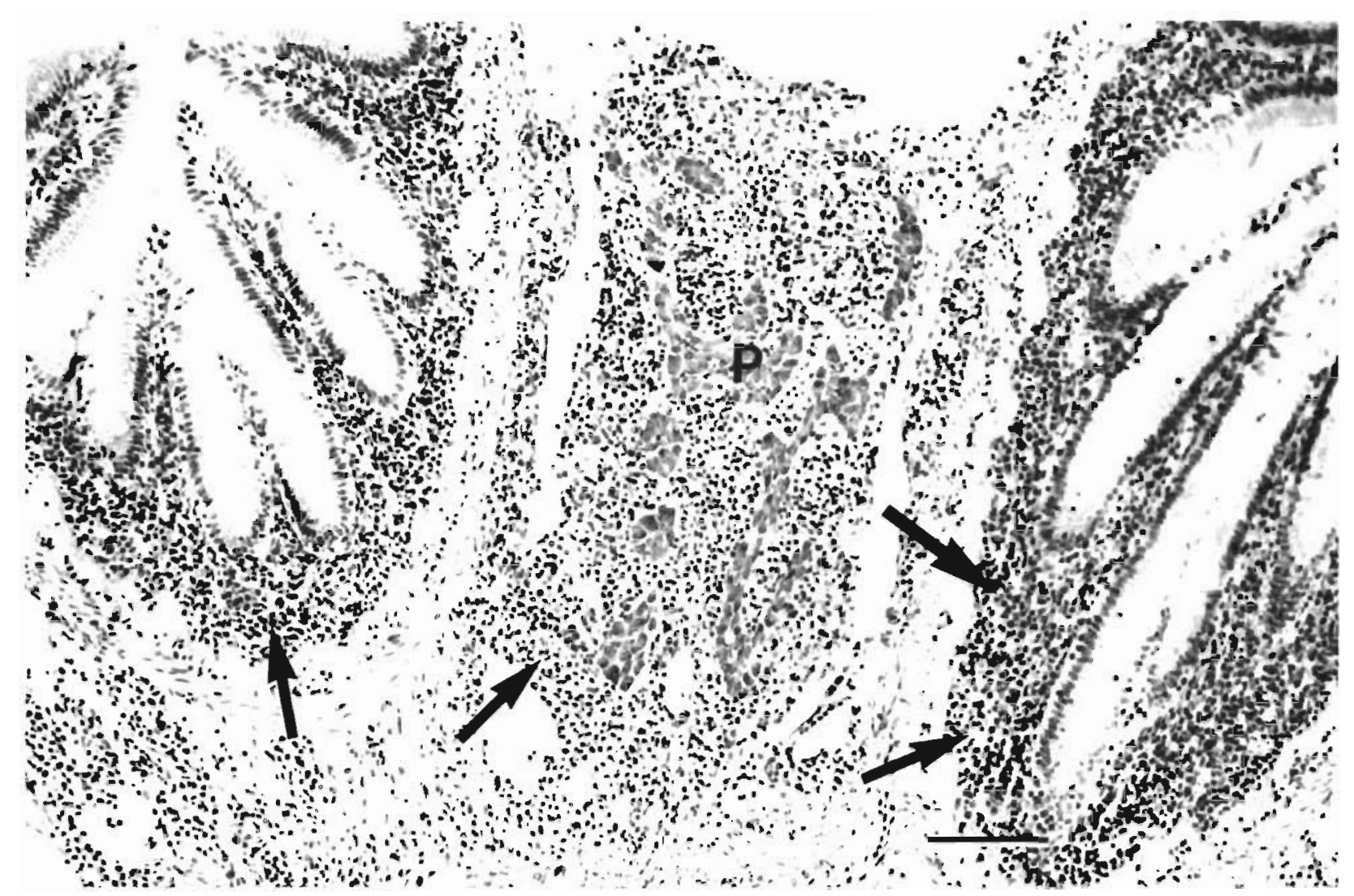

Fig. 3. Oncorhynchus tshawytscha. Proliferation of plasmablasts (arrows) in pancreas (P), associated fat and pyloric caeca in a chinook with PL that was treated with Fumagillin DCH. H\&E. Scale bar $=100 \mu \mathrm{m}$

(M. C. Schmale, University of Miami School of Medicine, Coral Gables, FL, USA, pers. comm.j.

Retroviruses have been associated with these lesions and other neoplasms of fishes (Papas et al. 1976, Duncan 1978, Yamamoto et al. 1985, Martineau et al. 1990, Anders et al. 1991). Retroviruses, including those that cause leukemias, are well recognized causes of immunosuppression. For example, many cats with FeLV (the cause of feline leukemia) die due to immunodeficiency-related problems rather than leukemia (Hoover \& Mullins 1991). Organisms with leukemias and other hemic proliferative disorders often succumb to secondary bacterial infections. Bacterial kidney disease is extremely prevalent in chinook in British Columbia, and virtually every stock is infected with Renibacterium salmoninarum (Brackett et al. 1991, Evelyn 1992). It was not surprising, therefore, that the stock of fish used for the filtrate experiment already was infected with the bacterium. BKD and PL often occur concurrently in netpens, and in the filtrate experiment BKD was more prevalent in the PL-exposed fish $(40 \%)$ than in the combined controls and stock population (5\%). Therefore, it is possible that PL or the $\mathrm{PL}$ agent causes immunosuppression and predisposes chinook to BKD. Conversely, agents that evoke chronic inflammation may exacerbate plasma cell neoplasms (Potter 1972), and R. salmoninarum may act as a promoting cofactor for PL. Field observations suggest this, in that PL in netpens is often observed in fish following BKD epizootics.

A disease that appears histologically very similar to PL has been reported in chinook reared in fresh water from Washington State (Morrison et al. 1990) and California (Hedrick et al. 1990, 1991). The microsporidium Enterocytozoon salmonis is found in most of these fish and has been suggested to be the cause of this disease. This parasite is often found in proliferating plasmablasts in fish with PL from netpens in British Columbia, and some have suggested that it is the cause of PL. Hedrick et al. (1991) reported that oral treatment with Fumagillin DCH prevented the parasite infection and the associated disease in chinook in California. The fish in their study were exposed by IP injection of whole infected lymphoblasts (= plasmablasts?), and the fish were treated with $1.5 \mathrm{mg}$ drug ( $\mathrm{kg}$ fish $^{-1} \mathrm{~d}^{-1}$ for $4 \mathrm{wk}$ starting at $3 \mathrm{wk}$ PI. In contrast, Fumagillin DCH had no effect on PL in the present study. In fact, if anything, Fumagillin DCH hastened 
the onset of PL. It is doubtful that the difference in efficacy of the drug in the 2 studies was due to differences in experimental protocol or dosage of the drug because the Fumagillin DCH used in our study was from the same lot as that used by Hedrick et al. (1991) and was provided to us by these researchers. In addition, we began treatment immediately after exposure as opposed to 3 wk PI, which was the protocol used in the study by Hedrick et al. (1991). As reported in our other transmission studies (Kent \& Dawe 1991, Newbound \& Kent 1991b), E. salmonis was not detected in any of the recipient fish, whereas the parasite was found in virtually all of the chinook with the PL-like disease in California. Therefore, based on results presented here, along with previous transmission studies (Kent \& Dawe 1990, Newbound \& Kent i999ibj, E. sdinumis is probably not the cause of PL, at least in British Columbia.

The differences between our experimental results and observations and those of Hedrick et al. (1990, 1991) suggest that, even though the histological pattern of the diseases in fish from British Columbia and California are very similar, we may be dealing with 2 different conditions, each caused by different agents. Future transmission experiments are underway or are planned to clarify the role of $R$. salmoninarum infections in PL, to elucidate the sequential gross, histologic and hematologic changes of the disease, and to examine a dose-response relationship with experimentallyinduced PL.

Acknowledgements. We thank Dr R. le Gouvello and staff at Sanofi Santé Nutrition Animale for analysis of Fumagillin $\mathrm{DCH}$, Dr R. P. Hedrick for providing Fumagillin DCH, Dr T P. T Evelyn for manuscript review, and G. Prosperi-Porta for technical assistance. Funded in part by the British Columbia Ministry of Agriculture and Fisheries and Natural Sciences and Engineering Research Council of Canada.

\section{LITERATURE CITED}

Anders, L., Hjlger, I., Möller, H. (1991). Lentivirus-like particles in connective tissue tumours of fish from German coastal waters. Dis. aquat. Org. 11: 151-154

Brackett, J., Newbound, G., Speare, D. (1991). A fall survey of saltwater morbidity and mortality of farmed salmon in British Columbia. Province of British Columbia, Ministry of Agriculture and Fisheries, Victoria

Bruno, D. W. (1986). Histopathology of bacterial kidney disease in laboratory infected rainbow trout, Salmo gairdner Richardson, and Atlantic salmon, Salmo salar L., with reference to naturally infected fish. J. Fish Dis.9: 523-527

Duncan, I. B. (1978). Evidence for an oncovirus in swimbladder fibrosarcoma of Atlantic salmon Salmo salar L. J. Fish Dis. 1: $127-131$

Eaton, W. D., Kent., M. L. (1992). A retrovirus in chinook salmon (Oncorhynchus tshawytscha) with plasmacytoid leukemia and evidence for the etiology of the disease Cancer Res. 52: 6496-6500

Evelyn, T P. T. (1992). Bacterial kidney disease: a review of recent findings and the outlook for its control. In: Roberts R. J. (ed.). Bacterial diseases of fish. Blackwell Scientific Publ., Oxford, p. 177-195

Gross, L. (1983). Oncogenic viruses. Pergamon Press, Toronto

Hedrick, R. P., Groff, J. M., Baxa, D. V. (1991). Experimental infections with Enterocytozoon salmonis Chilmonczyk, Cox, Hedrick (Microsporea): an intranuclear microsporidium from chinook salmon Oncorhynchus tshawytscha. Dis aquat. Org. 10: 103-108

Hedrick, R. P., Groff, J. M., McDowell, T S., Willis, M., Cox, W. T. (1990). Hematopoietic intranuclear microsporidian infections with features of leukemia in chinook salmon Oncorhynchus tshawytscha. Dis. aquat. Org. 8: 189-197

Hoover, E. D., Mullins, J. I. (1991). Feline leukemia virus infection and disease. J. Am. Vet. Med. Ass. 10: 1287-1297

Humasnn, G. L. (1979). Animal tissue techniques. W. H. Freeman Co., San Francisco

Kent, M. L., Dawe, S. C. (1990). Experimental transmission of a plasmacytoid leukemia of chinook salmon, Oncorhynchus tshawytscha. Cancer Res. (Suppl). 50: 5679-5681

Kent, M. L., Groff, J. M., Traxler, G. S., Zinkl, J. G., Bagshaw, J. W. (1990). Plasmacytoid leukemia in seawater reared chinook salmon Oncorhynchus tshawytscha Dis. aquat. Org. 8: 199-209

Kent, M. L., Traxler, G. S., Bagshaw, J. W.. McKay, J. A. (1989). A hemic proliferative disorder associated with severe anemia in pen-reared chinook salmon, Oncorhynchus tshawytscha. F.H.S. Newslett. 17(2): 7

Martineau, D., Bowser, P. R., Wooster, G. A., Armstrong, L. D (1990). Experimental transmission of a dermal sarcoma on fingerling walleyes (Stizostedion vitreum vitreum). Vet. Pathol. 27: 230-234

MacConnell, E., Shaw, T., Smith, C. E. (1991). Naturallyoccurring infection with intranuclear microsporidium Enterocytozoon saimonis, in steelhead trout Oncorhynchus mykiss. Abstracts - 14th annual AFS/FHS meeting, 31 Jul-3 Aug 1991, Newport, Oregon, USA. Fish Health Sec., American Fisheries Soc., Corvallis, p. 11

Morrison, J. K., MacConnell, E., Chapman, P. F., Westgard, R. L. (1990). A microsporidium-induced lymphoblastosis in chinook salmon Oncorhynchus tshawytscha in freshwater. Dis. aquat. Org. 8: 99-104

Mulcahy, M. F., O'Leary, A. (1970). Cell-free transmission of lymphosarcoma in the Northern pike Esox lucius L. (Pisces; Esocidae). Experientia 26: 891

Newbound, G. C., Kent, M. L. (1991a). Prevalence of plasmacytoid leukemia in British Columbia chinook salmon. Fish Health Sec./Am. Fish. Soc. Newslett. 19(1): 1-2

Newbound, G. C., Kent, M. L. (1991b). Experimental interspecies transmission of plasmacytoid leukemia in salmonid fishes. Dis. aquat. Org. 10: 159-166

Papas, T. S., Dahlberg, J. E., Sonstegard, R. A. \{1976\}. Type C virus in lymphosarcoma in northern pike (Esox lucius). Nature 261: 506-508

Potter, M. (1972). Immunoglobulin-producing tumors and myeloma proteins of mice. Phys. Rev. 52: 631-719

Sonstegard, R. A. (1979). Virus associated hematopoietic neoplasia in shellfish and fish. In: Yohn, D. S., Lapin, B., Blakeslee, J. R. (eds.) Advances in comparative leukemia research. Elsevier/North Holland, New York, p. 227

Wolke, R. E. (1975). Pathology of bacterial and fungal diseases affecting fish. In: Ribelin, W. E., Migaki, G. (eds.) Pathology of fishes. The University of Wisconsin Press, Madison, p. 33-116 
Wood, E. M., Yasutake, W. T. (1956). Histopathology of kidney disease in fish., Am. J. Pathol 32: 845-857

Yamamoto, T., Kelly, R. K., Nielsen, O. (1985). Morpholo-

Responsible Subject Editor: N. Peters, Hamburg, Germany gical differentiation of virus-associated skin tumors of walleye (Stizostedion vitreum vitreum). Fish Pathol. 20: $361-372$

Manuscript first received: May 26, 1992

Revised version accepted: October 20, 1992 